\title{
Inhibitory effects of omission training
}

\author{
JOHN A. NEVEN, RONALD MICHAUD, SUSAN KEEFE, and JUDITH SCHARFF \\ University of New Hampshire, Durham, New Hampshire 03824
}

\begin{abstract}
In Experiment 1, pigeons were trained to peck red or blue keys for food reinforcement at variable intervals, while food was contingent on withholding key pecks in the presence of a vertical line (omission training). When the line was briefly superimposed on red or blue in a compound test, responding was reduced. When the orientation of the line was varied during extinction, generalization gradients were variable but often had most responding at or near vertical. In Experiment 2, pigeons were trained in a discrete trials procedure that made food contingent upon pecking in the presence of triangle, and upon the absence of pecking in the presence of red (omission training). Fcod was never given on green-key trials (extinction). When red or green backgrounds were presented with the triangle in a compound test, responding was reduced similarly in the presence of both key colors. Subsequent resistance to autoshaping was also similar for red and green. These data, taken together with reports in the literature, suggest that the inhibitory effects of omission training are quite similar to those of extinction. Thus, the crucial condition for obtaining inhibitory effects is not a negative stimulus-reinforcer correlation, as in extinction, but simply the establishment of low rates of responding to the inhibitory stimulus.
\end{abstract}

A conventional discrimination training procedure involves the successive presentation of two stimuli, $\mathrm{S} 1$ and S2, correlated with independent schedules of reinforcement. When $S 1$ is correlated with variableinterval (VI) reinforcement and $\mathbf{S 2}$ is correlated with extinction, the following effects have been reported: (1) reduced responding when $S 2$ is compounded with S1; (2) retarded acquisition when the S2 schedule is changed from extinction to reinforcement; and (3) an incremental gradient with a minimum at S2 along a continuum that does not include S1. When any or all of these effects are observed as a result of the negative correlation of $\mathbf{S} 2$ and reinforcement, $S 2$ is commonly said to be an inhibitory stimulus. The interrelations of these inhibitory effects of S2, and their dependence on various parameters of operant discrimination training, have been discussed at length by Hearst (1972), Hearst, Besley, and Farthing (1970), and Rilling (1977).

Most of the early evidence for the existence of inhibitory processes was derived from incremental gradients (cf. Jenkins, 1965). Hearst and his associates have argued that an incremental gradient, by itself, is not sufficient to indicate an inhibitory effect. However,

Experiment 1 of this paper was conducted independently by the second author, and presented by him at the meetings of the American Psychological Association in September 1976. Experiment 2 was conducted by the third and fourth authors as a joint undergraduate project under the direction of the first author. Reprints may be obtained from the first author, Department of Psychology, University of New Hampshire, Durham, New Hampshire 03824. R. Michaud is now at Shriver Center, Waltham, Massachusetts.
Rilling's (1977) recent review suggests that, by and large, the conditions that generate reduced responding when stimuli are compounded will also generate incremental gradients of generalization. Retardation of learning ("resistance to reinforcement") has not been studied in enough situations to permit secure generalizations.

Hearst and his associates have also argued that a negative stimulus-reinforcer correlation "is crucial in endowing a stimulus with inhibitory properties" (Karpicke \& Hearst, 1975, p. 166). However, the negative correlation need not be perfect or even exist at all. Incremental gradients with minima at S2 have been obtained when reinforcement in S2 was infrequent relative to that in S1 (Weisman, 1969), when reinforcement in S2 was as frequent as in S1 but delayed (Richards, 1973), or when reinforcement in S2 was as frequent as in S1 but independent of responding, provided that reponse rates in S2 were clearly lower than in S1 (Weisman \& Ramsden, 1973). However, none of these studies examined the effects of stimulus compounding or resistance to reinforcement. If Hearst is correct that incremental gradients do not suffice to define inhibitory effects, other tests are needed.

It is worth noting that all three studies cited above established lower rates of responding in the presence of S2 than in S1. It is possible that the necessary and sufficient condition for inhibitory effects is simply a lower rate of responding in the presence of S2, rather than a negative stimulus-reinforcer correlation. The attempt to disentangle these factors with respect to behavioral contrast has been quite unsuccessful (see 
Mackintosh, 1974, p. 379). However, the question may be easier to address with respect to inhibitory effects.

A procedure of special interest in relation to the response-rate vs. stimulus-reinforcer correlation issue is omission training (also termed differential reinforcement of other behavior, DRO). In this procedure, a reinforcer is presented only if a designated response does not occur for some period of time. As a consequence, $\mathrm{S} 2$ will be correlated with a high rate of reinforcement if the rate of responding is low. Although Nevin (1968) failed to obtain incremental gradients when the rate of DRO reinforcement in S2 was appreciably greater than the rate of VI reinforcement in S1, Weisman (1970) reported convincing incremental gradients when the rates of DRO and VI reinforcement were equated. Again, however, the effects of stimulus compounding or resistance to reinforcement were not assessed, so the question of proper identification of inhibitory effects of $\mathrm{S} 2$ remains open.

In this report we describe the effects of omission training in the presence of $\mathbf{S} 2$ on keypecking by pigeons when $\mathrm{S} 2$ is compounded with $\mathrm{S} 1$ and when resistance to reinforcement is assessed. To the extent that the findings parallel those obtained when $\mathrm{S} 2$ is correlated with nonreinforcement, the significance of a negative stimulus-reinforcer correlation for the definition and demonstration of inhibitory effects is weakened. At the same time, an alternative argument to the effect that inhibition depends on the use of contingencies that establish low response rates may be strengthened.

The establishment of low rates in the presence of S2 by means of omission training does not, however, assure that inhibitory effects will be observed. When pigeons are exposed to omission training in discrete trials, they typically respond at substantial levels despite the response-contingent omission of food (Williams \& Williams, 1969; Woodard, Ballinger, \& Bitterman, 1974). Moreover, when stimuli signaling response-independent food are projected on a response key, a common result is increased pecking relative to baseline (LoLordo, 1971; Schwartz, 1976), especially if the signal is brief (Smith, 1974). Thus, the correlation of S2 with food may have excitatory effects that will override the inhibitory effects deriving from the low response rate in its presence. We report two experiments, one with free-operant omission training (DRO) that employs a brief presentation of $S 2$ in the compounding test, and one with brief discrete trials, to evaluate these possibilities.

\section{EXPERIMENT 1}

This study examined the effects of DRO training in the presence of $S 2$ in a free-operant procedure. The effects of S1-S2 compounding and stimulus gen- eralization along the $\mathbf{S} 2$ continuum were explored in a procedure that roughly paralleled those of Davis (1971) and Yarczower and Curto (1972), who employed extinction in S2. Both of those studies reported clear suppression of responding when $\mathrm{S} 2$ was compounded with S1, but did not obtain orderly incremental gradients along the $\mathbf{S} 2$ continuum.

\section{Method}

Subjects. Five White Carneaux pigeons, maintained at $80 \%$ of their free-feeding weights served. All were experimentally naive.

Apparatus. The experiment was conducted in a three-key Lehigh Valley pigeon chamber. The center key could be transilluminated by an IEE projector with uniform red, blue, or green light, or by a white line on a dark background. Orientations of $0^{\circ}$ (vertical), $\pm 20^{\circ}, \pm 40^{\circ}, \pm 60^{\circ}$, and $\pm 80^{\circ}$ were available. The side keys were never lighted, and pecks to the side keys had no consequences. A grain magazine was located below the center key, and a houselight was located above it. Electromechanical programming and recording equipment were in an adjacent room.

Procedure. Preliminary training consisted of magazine training, handshaping to peck the key, and gradual introduction of a VI 1-min schedule of food reinforcement, with green light on the key. When responding was well established, Phase I (nondifferential reinforcement) was instituted. Each session consisted of eight 90 -sec presentations each of red, blue, or the vertical white line on a dark background. These presentations occurred in irregular order, separated by a 5 -sec time-out during which the key was darkened. A single VI 1-min tape arranged reinforcers in the presence of all three stimuli. This phase lasted for 12 sessions.

Phase II consisted of differential reinforcement, with a DRO 30 -sec schedule in the presence of the vertical line while VI 1-min reinforcement continued in the presence of red and blue. The DRO schedule arranged for food presentation $30 \mathrm{sec}$ after onset of the vertical line, and after each subsequent food presentation if no keypecks occurred. Each keypeck reset the 30 -sec interval.

Tests for stimulus generalization along the line-orientation continuum, and for reduced responding when the white line was superimposed upon the red or blue key, were conducted twice during this phase. The first test was conducted after the first session in which at least 10 DRO reinforcers were obtained, and the second after 12 additional training sessions. The effects of compounding were assessed with two birds, and generalization tests were conducted with the other three. The entire cycle of Phase I training with equal reinforcement and Phase II training with differential reinforcement was then repeated, with the birds initially tested for the effects of compounding now receiving generalization tests, and vice versa, at comparable points in the replication of Phase II.

The stimulus compounding test was conducted in a single session by superimposing the vertical white line on the red or blue key during a random half of the stimulus periods. Each 90 -sec cornpounding test period began with $30 \mathrm{sec}$ of uniform red or blue light, with the line superimposed during the next $30 \mathrm{sec}$, followed by $30 \mathrm{sec}$ with red or blue only. This procedure is analogous to a standard conditioned suppression procedure, in which the effects of a signal can be assessed relative to a presignal period. In addition, postsignal recovery can be examined. Tests were conducted with both red and blue as a preliminary to further work in which different schedules will be correlated with two key colors. Food was never presented during a compound test period.

Stimulus generalization tests were conducted in a single session during extinction, with eight line orientations (six for the three birds in the first test) presented in five randomized blocks. No colors were ever presented on the key. Each line presentation lasted $30 \mathrm{sec}$, separated by $10-\mathrm{sec}$ periods with the key darkened. A 21-min warm-up period with Phase II contingencies preceded each generalization test. 


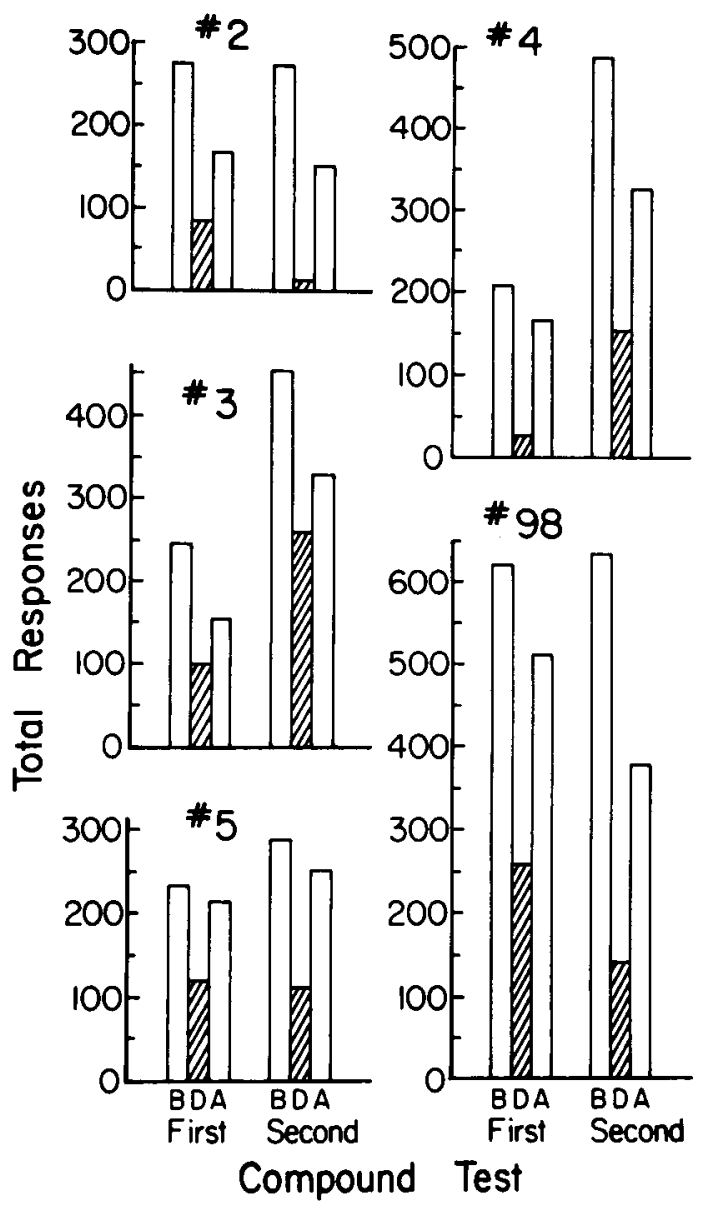

Figure 1. Effects of presenting a vertical line correlated with omission training (DRO) on reponding in the presence of a key color correlated with variable-interval reinforcement. Results are presented for two tests for each subject, indicating numbers of responses in successive 30 -sec periods before $(B)$, during $(D)$, and after (A) presentation of the vertical line.

\section{Results}

Response rates stabilized rapidly during Phase I, with no consistent differences in responding to the three stimuli: red, blue, and vertical line. When the schedule correlated with the vertical line was changed from VI 1-min to DRO 30-sec in Phase II, response rates in the presence of the vertical line decreased to near-zero levels over the course of 6 to 10 sessions, with little change in response rates in the presence of red and blue. After the first few sessions, the rate of reinforcement obtained in the presence of the vertical line approximated those in the presence of red and blue.

Data for the first and second compound test sessions are presented in Figure 1. Because there was no consistent difference in either baseline performance or in compound tests with red or blue light on the key, the data have been combined for these two key colors. For all subjects, in both the first and second tests, superimposing the vertical line during the middle portion of the test period resulted in a substantial reduction of responding, followed by partial recovery. On the average, responding during the vertical line was $32 \%$ of the prestimulus level during the first test, and $31 \%$ during the second test. Birds tested during the first and the second Phase II treatment did not differ consistently. Thus, it appears that a stimulus correlated with omission training has clear and consistent inhibitory effects when compounded with a stimulus correlated with VI reinforcement, and that the suppressive effect is independent of length of training over the range examined here.

Gradients of responding for the first and second generalization tests are presented in Figure 2. None of the five birds exhibit clear incremental gradients, and for several birds the gradients have maxima at or near $0^{\circ}(\mathrm{S} 2)$. The second generalization test typically resulted in less total responding than the first, but there were no other consistent differences. Also, there was no consistent evidence of differences in the level or form of the gradient between birds tested during the first (Birds 3, 5, and 98) and the second (Birds 2, 4) exposure to Phase II. In summary, the

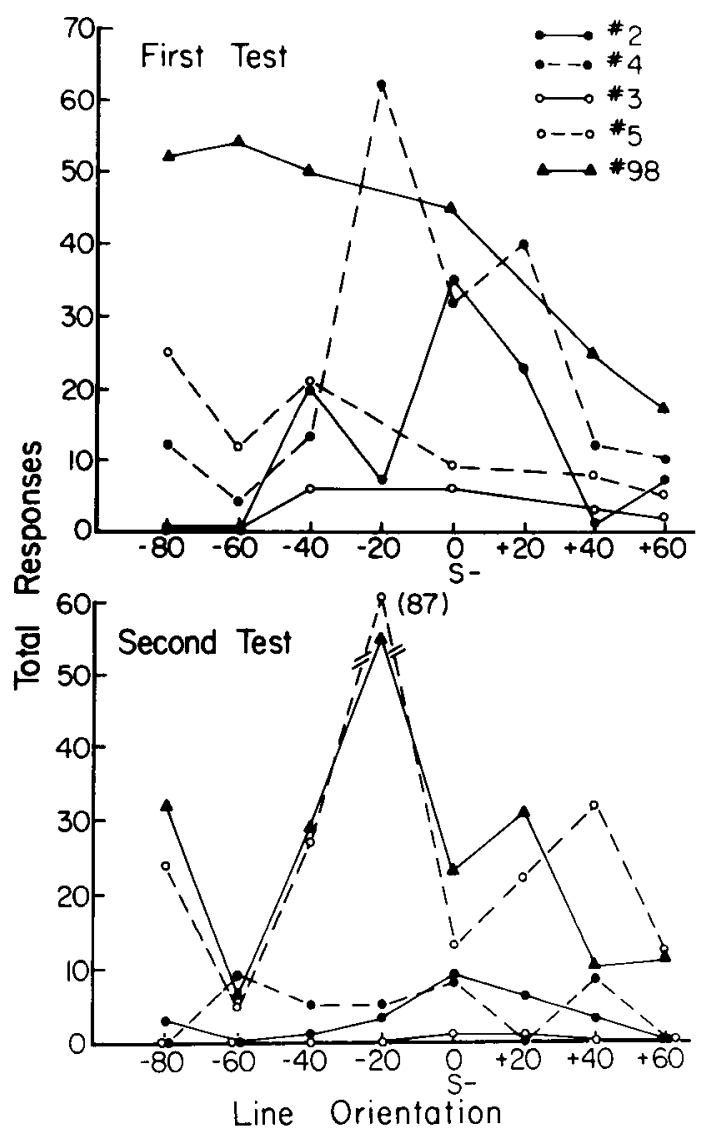

Figure 2. Generalization gradients taken during extinction after ommission training (DRO) in the presence of a vertical line $\left(0^{\circ}\right)$. Total responses to each orientation are presented separately for individual subjects for two successive generalization tests. 
generalization data give no evidence of inhibitory stimulus control; if anything, control appears to be excitatory, in that stimuli in the region of S2 tend to command the largest numbers of responses.

\section{EXPERIMENT 2}

Experiment 1 demonstrated an inhibitory effect of a vertical line correlated with omission training (DRO) when it was compounded with stimuli correlated with VI reinforcement. The magnitude of the effect was comparable to that observed when a vertical line was correlated with nonreinforcement (Davis, 1971; Yarczower \& Curto, 1972). Although the gradients of generalization to line oreintation were not incremental-indeed, if anything, they were decrementalthis result also has precedent in studies where a vertical line has been correlated with extinction (Davis, 1971). Thus, a stimulus correlated with reinforcement for not responding seems to have effects that are quite similar to those sometimes reported for stimuli correlated with nonreinforcement. Experiment 2 explores this similarity within subjects in a discretetrials paradigm, with both compounding and resistance to reinforcement methods to assess inhibitory effects.

\section{Method}

Subjects. Four White Carneaux pigeons, maintained at $80 \%$ of their free-feeding weights, served as subjects. All had had prior exposure to nondifferential autoshaping with monochromatic lights on the key in a different, single-key chamber.

Apparatus. The experiment was conducted in a pigeon chamber with three Plexiglas sides and a standard three-key Lehigh Valley pigeon panel on the fourth side. The center key could be transilluminated with uniform red or green light, or by a white triangle, $.8 \mathrm{~cm}$ on a side. The side keys were never lighted, and pecks to the side keys had no consequences. A grain magazine was located below the center key, and a houselight was located above it. Electromechanical programming and recording equipment were in the same room as the chamber.

Procedure. Despite their histories, none of the pigeons pecked the lighted key when first introduced to the chamber. Accordingly, they were hand-shaped to peck the key with equal numbers of regular reinforcements in the presence of red, green, and triangle.

After all birds were responding reliably to each of the stimuli, a discrete-trials procedure was placed in effect with differential reinforcement in the presence of the three stimuli. After a variable intertrial interval lasting $30 \mathrm{sec}$ on the average, the key was lighted with the white triangle or a uniform red or green light. These were presented in irregular order and with equal frequency in blocks of 33 trials. The key light remained on for $6 \mathrm{sec}$, regardless of the subject's behavior. If the triangle appeared on the key, food was presented for $4 \mathrm{sec}$ at the end of the trial if the bird had pecked at least once during the trial. If the key was lighted red, food was presented at the end of the trial only if the bird had refrained from pecking throughout the entire $6-\mathrm{sec}$ trial (omission training, or negative automaintenance). If the key was lighted green, the trial terminated without food after 6 sec regardless of whether the bird pecked or not (extinction). This procedure remained in effect for 16 daily sessions of 66 trials per session.

The inhibitory effects of red or green were then assessed durin ${ }_{\dot{\varepsilon}}$ an extinction test session. There were five kinds of trials: triangle alone, red alone, green alone, triangle on a red surround, and triangle on a green surround. The latter two trial types assessed the extent to which responding to the triangle was reduced by stimuli correlated with omission training or extinction, respectively. The session consisted of 13 presentations each of the training stimuli, and 12 presentations of each of the compounds.

Resistance to reinforcement was assessed during seven sessions after the extinction test, using a conventional autoshaping procedure. The three training stimuli were presented in random order in 66-trial sessions as before, but now food was presented at the end of each trial regardless of the stimulus projected on the key or the subject's behavior in its presence.

\section{Results}

Figures 3 and 4 present the course of acquisition and the final resistance-to-reinforcement phase of the study, in terms of number of trials with a peck (Figure 3) and total pecks (Figure 4). During the 16 sessions of training, all birds pecked the triangle on nearly every trial, and pecked the red key quite frequently throughout training, while green-key pecking nearly ceased. The same orderings were evident in total keypecks, but the difference between total pecks to red and green was not so great as between the numbers of trials with a peck. These acquisition

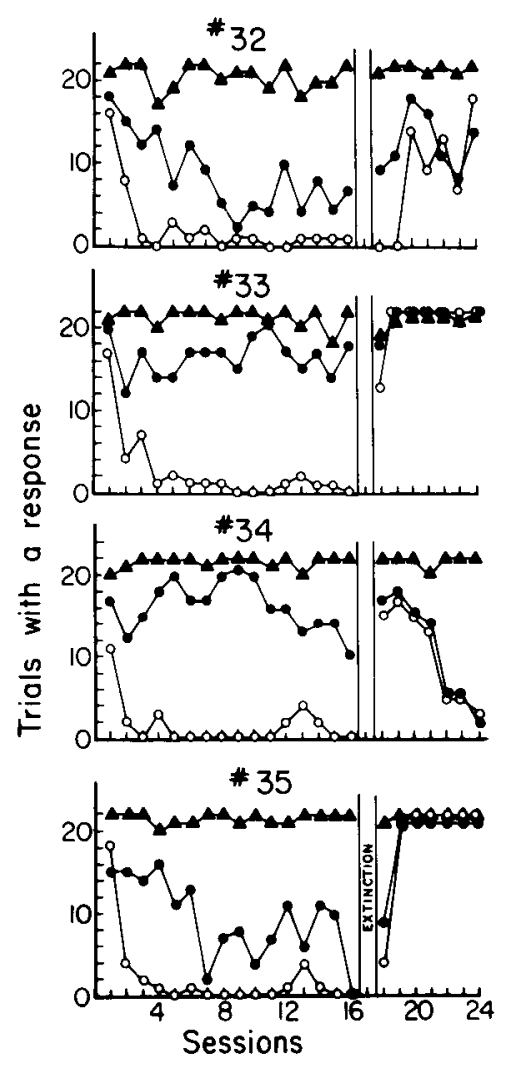

Figure 3. Number of trials per session with at least one keypeck to a triangle (filled triangles), a red key (filled circles), and a green key (unfilled circles) during the course of Experiment 2. During the $\mathbf{1 6}$ sessions before extinction, food was presented if the birds pecked at least once in the presence of the triangle and refrained from pecking in the presence of red, while food was never given in green. During the sessions after extinction, all three stimuli were followed by food regardless of the subjects' behavior. 


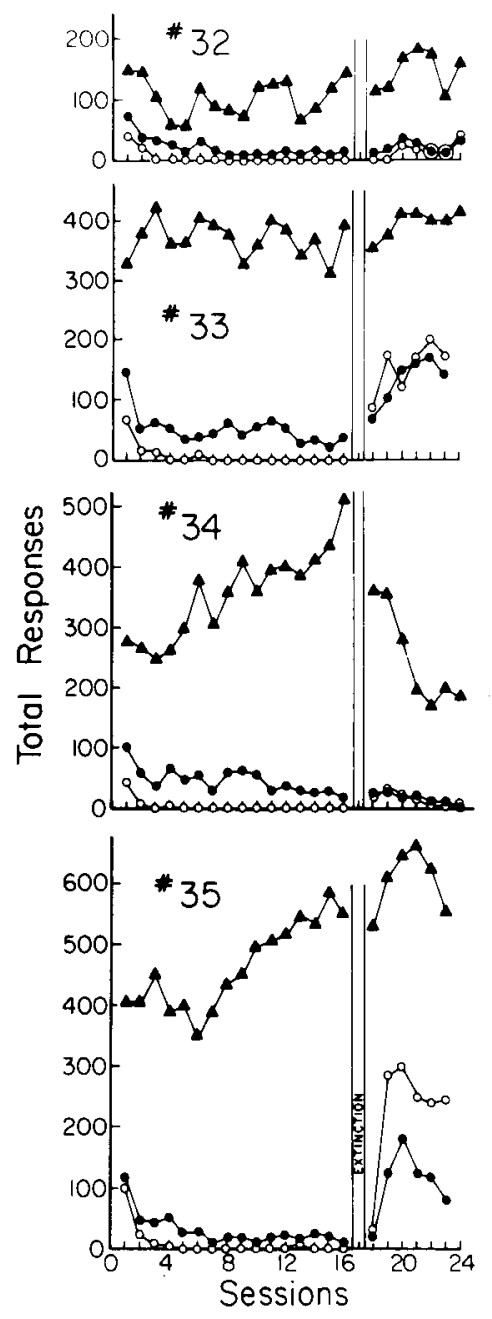

Figure 4. Total responses in the presence of triangle, red, and green under the conditions described for Figure 3.

data replicate those reported by Woodard, Ballinger, and Bitterman (1974).

Data for the extinction test session, when red and green were compounded with the white triangle, are summarized in Table 1. Both red and green surrounds reduced responding to the triangle to levels that were only slightly above those in the presence of red and green alone. Because all birds responded more to red alone than to green alone, comparisons were based on a suppression ratio corrected for maximum expected suppression to each color, as follows. The numerator was pecks to triangle alone minus pecks to triangle plus colored surround, and the denominator was pecks to triangle alone minus pecks to colored key alone, giving a ratio of the suppression produced by the colored surround to the maximum decrement expected if the colored surround suppressed pecks to the triangle entirely. The results of these computations, also presented in Table 1 , indicate that both red and green were strongly inhibitory, with no consistent difference between them.

When all three stimuli were correlated with response-independent food after the extinction test, responding to the triangle increased rapidly to its former level, while responding to both red and green increased slowly and erratically for most subjects (Bird 34 exhibited a decrease after the first few sessions). There was no consistent evidence of any difference in resistance to autoshaping in the presence of red and green. Thus, both the compounding and resistance-to-reinforcement data suggest that red, correlated with omission training, and green, correlated with nonreinforcement, were equally inhibitory.

\section{Discussion}

The data from Experiments 1 and 2 show clear response suppression during compound testing. Experiment 1 demonstrated that a stimulus correlated with DRO could affect behavior in ways very similar to those reported in studies employing nonreinforcement in the presence of S2 (Davis, 1971; Yarczower \& Curto, 1972). All subjects exhibited a decrease in response rate to S1 when S2 was superimposed during the compound period. In addition, there was no difference in suppression between the first and second test sessions, a result which, in part, replicates Yarczower and Curto (1972). Thus, as with extinction, inhibitory effects of stimuli correlated with DRO occur early and thereafter remain unchanged by further training.

In Experiment 2, both red (omission training) and green (extinction) stimuli suppressed responding during compounding with no systematic differences between the two, despite their different correlations with food and the consistently different levels of key-

Table 1

Number of Keypecks and Number of Trials With at Least One Peck (in Parentheses) During the Compounding Test

\begin{tabular}{|c|c|c|c|c|c|c|c|}
\hline \multirow[b]{2}{*}{ Bird } & \multirow[b]{2}{*}{$\begin{array}{c}\text { Triangle } \\
\text { (Reinforcement) }\end{array}$} & \multirow[b]{2}{*}{$\begin{array}{c}\text { Green } \\
\text { (Extinction) }\end{array}$} & \multirow[b]{2}{*}{$\begin{array}{c}\text { Red } \\
\text { (Omission) }\end{array}$} & \multirow[b]{2}{*}{$\begin{array}{c}\text { Green and } \\
\text { Triangle } \\
\text { (Test) }\end{array}$} & \multirow[b]{2}{*}{$\begin{array}{c}\text { Red and } \\
\text { Triangle } \\
\text { (Test) }\end{array}$} & \multicolumn{2}{|c|}{ Corrected Suppression Ratio } \\
\hline & & & & & & $\begin{array}{l}\text { Green and } \\
\text { Triangle }\end{array}$ & $\begin{array}{l}\text { Red and } \\
\text { Triangle }\end{array}$ \\
\hline 32 & $55(10)$ & $0(0)$ & $3(2)$ & $9(2)$ & $15(6)$ & .84 & .77 \\
\hline 33 & $163(13)$ & $0(0)$ & $12(7)$ & $1(1)$ & $6(3)$ & .99 & 1.04 \\
\hline 34 & $311(13)$ & $0(0)$ & $10(7)$ & $27(5)$ & $67(11)$ & .91 & .81 \\
\hline 35 & $346(13)$ & $0(0)$ & $13(9)$ & $1(1)$ & $6(3)$ & 1.00 & 1.02 \\
\hline
\end{tabular}


pecking in their presence. Compounding data for green are essentially identical to those of Wessells (1973), who demonstrated that a stimulus correlated with nonreinforcement in a differential autoshaping procedure suppressed responding to near zero levels when compounded with a stimulus that had been correlated with food. In addition, responding was about equally resistant to autoshaping in the presence of red and green, suggesting that the inhibitory ef fects of omission training are quite similar to those of nonreinforcement in both compounding and resistance-to-reinforcement tests.

The situation is less clear with respect to gradients of generalization about S2. Although Farthing and Hearst (1968), Honig, Boneau, Burstein, and Pennypacker (1963), and Nevin (1968) have reported reliable incremental gradients on a line-orientation continuum when extinction was correlated with a vertical line, neither Davis (1971) nor Yarczower and Curto (1972) obtained orderly gradients under similar conditions. Likewise, reliable incremental gradients were obtained by Weisman (1970) after training with DRO in the presence of a vertical line, while neither Nevin (1968) nor the present Experiment 1 obtained incremental gradients under comparable conditions. Evidently, incremental gradients are complexly determined, and are not sufficient indicators of inhibitory processes, as Hearst and his associates have suggested.

Taken together with earlier studies, our findings suggest that stimuli correlated with omission training (DRO) are at least as inhibitory as are stimuli correlated with nonreinforcement. Thus, it would appear that the crucial condition for demonstrating inhibitory effects in stimulus compounding, resistance to reinforcement, and stimulus generalization (when orderly gradients are obtained) is not the stimulus-food correlation but simply the use of a contingency that produces low rates of responding in the presence of $\mathrm{S} 2$.

Although this assertion is consistent with the available literature, it contrasts with Hearst's argument that a negative correlation between a stimulus and a reinforcer is necessary for that stimulus to acquire inhibitory properties. Hearst's argument is based on the assumption that contingencies that produce low rates by means of positive stimulus-reinforcer contingencies (e.g., DRO) involve excitatory counterconditioning of some unspecified response. Thus, the response suppression observed during compounding in Experiments 1 and 2, and the resistance to reinforcement observed in Experiment 2, would be said to result from an unspecified response which was shaped by the DRO contingencies and which interfered with the expression of keypecking (e.g., active waiting, wall-pecking, magazine approach, etc.). This is entirely plausible. However, there is good reason to believe that a similar process occurs with nonreinforcement. The interference theory of extinction, which dates back at least to Guthrie (1935; see Kimble, 1961, for review) assumes that extinction occurs because of the increase of some competing response. There may be an explicit source of reinforcement for competing behavior in the presence of an extinction stimulusfor example, reduction of conditioned aversive stimulation-which is functionally equivalent to positive reinforcement in omission training. Consistent with this speculation, several investigators have demonstrated that pigeons will learn a new response that terminates a stimulus correlated with extinction (e.g., Rilling, Askew, Ahlskog, \& Kramer, 1969; Terrace, 1971). Moreover, Rand (1977) has reported that without any explicit escape contingencies, stereotyped behavior patterns that compete with keypecking develop in the presence of an extinction stimulus. Thus, there is no compelling reason to believe that the conditioning of active competing responses is unique to contingencies of positive reinforcement such as omission training.

The argument that response reductions attributed to inhibition depend on increases in other activities that compete with the measured response has been stated by Catania $(1969$, p. 741$)$ and Jenkins $(1965$, p. 59). In a different context, Weiss (1972) referred to the observation that responding may be reduced by stimulus compounding as "response averaging" rather than inhibition, and discussed the effect in terms of the blending of the performances separately conditioned to the two stimuli being compounded. These ways of speaking about inhibitory effects have the advantage of referring to behavior that can, in principle, be specified and measured, rather than to some associative process that is not defined directly at the level of behavior. As such, they encourage the study of experimentally produced changes in behavior that determine inhibitory effects.

\section{REFERENCES}

Catania, A. C. Concurrent performances: Inhibition of one response by reintorcement of another. Journal of the Experimental Analysis of Behavior, 1969, 12, 731-744.

Davis, J. M. Testing for inhibitory stimulus control with $\mathrm{S}$ - superimposed on $\mathrm{S}+$. Journal of the Experimental Analysis of Behavior, 1971, 15, 365-369.

Farthing, G. W., \& Hearst, E. Generalization gradients of inhibition after different amounts of training. Joumal of the Experimental Analysis of Behavior, 1968, 11, 743-752.

Guthrie, E. R. The psychology of learning. New York: Harper, 1935.

Hearst, E., Besley, S., \& Farthing, G. W. Inhibition and the stimulus control of operant behavior. Journal of the Experimental Analysis of Behavior, 1970, 14, 373-409.

HEARST, E. Some persistent problems in the analys is of conditioned inhibition. In R. A. Boakes \& M. S. Halliday (Eds.), Inhibition and leaming. New York: Academic Press, 1972.

Honig, W. K., Boneau, C. A., Burstein, K. R., \& Pennypacker, H. S. Positive and negative generalization gradients obtained after equivalent training conditions. Journal of Comparative and Physiological Psychology, 1963, 56, 111-116. 
JENKINS. H. M. Generalization gradients and the concept of inhibition. In D. 1. Mostofsky (Ed.). Stimulus generalization. Stanford: Stanford University Press. 1965.

KaRPICKE, J., \& HeARst, E. Inhibitory control and errorless d 5crimination learning. Journal of the Experimental Analysis of Behatior, 1975, 23, 159-166.

Kıмвде, G. A. Hilgard and Marquis' conditioning and learning. New York: Appleton-Century-Crofts. 1961.

LoLoRDo. V. M. Facilitation of food-reinforced responding by a signal for response-independent food. Journal of the Experimental Analysis of Behavior, 1971, 15, 49-55.

Mackintosh. N. J. The psychology of amimal learning. New York: Academic Press, 1974.

Nevin. J. A. Differential reinforcement and stimulus control of not responding. Journal of the Experimental Analysis of Behavior. $1968,11,715.726$.

RAND. J. F. Behaviors observed during $S$ - in a simple discrimination learning task. Joumal of the Experimental Analysis of Behavior, 1977. 27, 103.117.

RichaRDs, R. W. Stimulus generalization and delay of reinforcement during one component of a multiple schedule. Joumal of the Experimental Analysis of Behavior, 1973, 19, 303-309.

Rilling, M. Stimulus control and inhibitory processes. In W. K. Honig \& J. E. R. Staddon (Eds.). Handbook of operant behavior. New York: Prentice-Hall, 1977.

Rilling. M., Askew, H. R., Ahlskog, J. E., \& Kramer, T. J. Aversive properties of the negative stimulus in a successive discrimination. Joumal of the Experimental Analysis of Behavior, 1969. 12, 917-932.

SChwartz, B. Positive and negative conditioned suppression in the pigeon: Effects of the locus and modality of the CS. Learning and Motivation, 1976, 7, 86-100.

Smiтh. F. B. Effects of response rate, reinforcement frequency, and the duration of a stimulus preceding response-independent food. Journal of the Experimental Analysis of Behavior, 1974. 21. 215-221.

Terrace, H. S. Escape from S-. Learning and Motivation. 1971. 2. 148-163.

Weisman. R. G. Some determinants of inhibitory stimulus control. Journal of the Experimental Analysis of Behavior, 1969, 12, 443-450.

WEISMAN, R. G. Factors intluencing inhibitory control: Differential reintorcement of other behavior during discrimination training. Journal of the Experimental Analysis of Behavior. 1970, 14. 87-91.

WeIsman. R. G., \& RamsDen. M. Discrimination of a responseindependent component in a multiple schedule. Journal of the Experimental Analysis of Behavior, 1973, 19. 55-64.

WeIss. S. J. Stimulus compounding in free-operant and classical conditioning: A review and analysis. Psychological Bulletin. 1972. 78, 189-208.

WeSSELLS, M. G. Errorless discrimination, autoshaping, and conditioned inhibition. Science, 1973, 182, 941-943.

Williams, D. R.. \& Williams, H. Automaintenance in the pigeon: Sustained pecking despite contingent notreinforcement. Journal of the Experimental Analysis of Behavior. 1969. 12. 511-520.

Woodard, W. T., Ballinger, J. C., \& Bitterman, M. E. Autoshaping: Further study of "negative automainienance." Journal of the Experimental Analysis of Behavior, 1974, 22, 47-51.

Yarczower, M.. \& Curto. K. Stimulus control in pigeons after extended training. Journal of Comparative and Physiological Psychology. 1972, 80, 484-489.

(Received for publication July 11, 1978; revision accepted September 28 , 1978.) 